\title{
Atherosclerotic vascular disease is more prevalent among black ESKD patients on long-term CAPD in South Africa
}

\author{
S. O. Oguntola ${ }^{1 *}$, M. O. Hassan ${ }^{4}$, R. Duarte ${ }^{3 \dagger}$, A. Vachiat ${ }^{2}$, P. Manga ${ }^{2}$ and S. Naicker ${ }^{1+}$
}

\begin{abstract}
Background: Occurrence of cardiovascular disease (CVD) in the setting of chronic kidney disease (CKD) can be described as a "cruel alliance", with CVD responsible for about half of all deaths among CKD patients. Chronic kidney disease patients are more likely to die from CVD than progress to end stage kidney disease (ESKD). Dyslipidaemia, a known traditional risk factor for CVD, is highly prevalent among CKD patients and with an even higher frequency among ESKD patients on dialytic therapies. Prolonged exposure of continuous ambulatory peritoneal dialysis (CAPD) patients to high glucose concentrations in CAPD fluid have been associated with increased risk of cardiovascular events. In this study, we investigated the relationship of atherosclerotic vascular disease (AsVD) to clinical and echocardiographic parameters among black South Africans with CKD (stage 3) and ESKD on CAPD and haemodialysis (HD).

Methods: This was a cross-sectional study of 40 adult (18-65 years) non-diabetic CKD patients (kidney disease outcome quality initiative [KDOQI] stage 3), 40 ESKD patients on CAPD, 40 ESKD patients on HD and 41 age and sex-matched healthy controls. An interviewer-administered questionnaire was used to obtain information on participants' sociodemographic and cardiovascular risk factors. Anthropometric parameters were measured. Serum blood samples were analysed for creatinine, albumin and lipid profile; lipoprotein ratios, Framingham's risk score and the 10-year risk of developing coronary heart disease (CHD) were calculated. Echocardiography was performed on all patients and carotid intima media thickness (CIMT) was measured in both right and left carotid arteries at 1 $\mathrm{cm}$ proximal to the carotid bulb. Spearman's rank correlation and binary logistic regression were conducted to determine the relationship of AsVD to clinical and echocardiographic parameters.

Results: Atherosclerotic vascular disease was most prevalent among ESKD patients on CAPD $(70 \%, n=28 / 40)$. Chronic kidney disease and HD patients exhibited a similar prevalence $(47.5 \%, n=19 / 40)$, while the prevalence in controls was $17.1 \%(n=7 / 41)$. Presence of AsVD was associated with significantly older age, higher waist hip ratio (WHR), left ventricular mass index (LVMI) and Framingham's 10-year risk of developing CHD. Significant differences in clinical and echocardiographic parameters were observed when the study groups were compared. Age and LVH independently predicted AsVD.
\end{abstract}

Conclusion: Atherosclerotic vascular disease was more prevalent among CAPD patients compared to pre-dialysis CKD and HD patients. Among all lipoprotein ratios assessed, non-HDL-C showed the most consistent significant difference between the groups. Age (> 40 years) and presence of LVH were independent predictors of AsVD.

Keywords: Atherosclerotic vascular disease, Continous ambulatory peritoneal dialysis, Haemodialysis, Chronic kidney disease, End-stage kidney disease, Left ventricular hypertrophy

\footnotetext{
*Correspondence: olawaleogun1@gmail.com; olawaleogun1@gmail.com

${ }^{\dagger} \mathrm{R}$. Duarte and S. Naicker are joint senior authors

'Department of Internal Medicine, Division of Nephrology, Faculty of Health

Sciences, University of Witwatersrand, 7, York Street, Parktown, Johannesburg,

South Africa

Full list of author information is available at the end of the article
}

(c) The Author(s). 2019 Open Access This article is distributed under the terms of the Creative Commons Attribution 4.0 International License (http://creativecommons.org/licenses/by/4.0/), which permits unrestricted use, distribution, and reproduction in any medium, provided you give appropriate credit to the original author(s) and the source, provide a link to the Creative Commons license, and indicate if changes were made. The Creative Commons Public Domain Dedication waiver (http://creativecommons.org/publicdomain/zero/1.0/) applies to the data made available in this article, unless otherwise stated. 


\section{Introduction}

Robust association exists between chronic kidney disease (CKD) and cardiovascular disease (CVD) [1], of which, atherosclerotic vascular disease (AsVD) contributes significantly to morbidity and mortality in CKD [2]. Atherosclerotic vascular disease was found to be related to $60.9 \%$ of deaths among non-diabetic end stage kidney disease (ESKD) patients on maintenance haemodialysis (HD) [3]. As the estimated glomerular filtration rate (eGFR) deteriorates, cardiovascular complications emerge and increase in frequency as CKD progresses [4]. A report of the baseline characteristics of participants from the Chronic Renal Insufficiency Cohort (CRIC) study showed that lower levels of eGFR were associated with a higher prevalence of CVD [5]. Similarly, the Atherosclerotic Risk In Community (ARIC) study found a consistent association between increased left ventricular mass and low eGFR [6]. In the sub-Saharan African setting, a study found cardiac lesions to be highly prevalent among ESKD patients on maintenance $\mathrm{HD}$, with left ventricular hypertrophy ( $\mathrm{LVH})$ being the most common cardiac lesion [7]. A case control study among black South African ESKD patients found a high prevalence of carotid plaques (38.1\%) among ESKD patients on maintenance HD compared to controls (7.9\%) [8]. Similarly, coronary calcification was present in $38.6 \%$ of ESKD patients in another South African study and was associated with older age and previous CVD [9]. Although this study recruited both HD and CAPD patients, nearly $90 \%$ of the participants were on HD [9]. Studies designed to assess CVD in black South African ESKD patients on CAPD are sparse, despite increased CVD-related morbidity and mortality seen in this group of patients $[10,11]$. A study on the predictors of mortality among rural dwelling ESKD patients on chronic dialysis found continuous ambulatory peritoneal dialysis (CAPD) to be a predictor of all-cause mortality [11], hence there is the need to investigate CVD in both HD and CAPD patients.

Dyslipidaemia is recognized as a traditional risk factor for CVD. Furthermore, abnormalities in lipid metabolism related to uraemia have been reported [12]. A rise in the prevalence of atherogenic dyslipidaemia in the black population in an urban settlement in Cape Town, South Africa has been noted; $59 \%$ of ischaemic heart disease and $29 \%$ of ischaemic stroke burden in males and females $\geq 30$ years were attributable to increased cholesterol levels in this population [13]. Some studies have reported that dyslipidaemia, such as an increase in low density lipoprotein (LDL-C), triglycerides (TG), lipoprotein (a) (LPa) and reduced high density lipoprotein (HDL-C) are more commonly seen in PD than HD patients $[14,15]$.

The high prevalence of dyslipidaemia in the urban population of South Africa, the association between dyslipidaemia and CKD and the evidence of higher mortality in PD when compared to $\mathrm{HD}$, impelled us to evaluate the prevalence and the determinants of atherosclerotic vascular disease in CKD (stage 3) and ESKD patients on dialysis (both CAPD and HD).

\section{Methods}

This was a cross-sectional study of 40 adult (age 18-65 years) non-diabetic ESKD patients on maintenance HD, 40 ESKD patients on CAPD, 40 stage 3 CKD patients and 41 age- and sex-matched healthy controls at a large urban public hospital in South Africa from 2 January 2017 to 31 August 2017. The CAPD patients were on 4 exchanges per day of 21 bags of conventional (glucosebased) PD fluid, while the HD patients were on thrice weekly maintenance dialysis on bicarbonate dialysate using a high flux dialyzer with biocompatible membranes, dialysate flow rate of $500 \mathrm{ml} / \mathrm{min}$ and moderate blood flow rate of $350 \mathrm{ml} / \mathrm{min}$. Black patients were selected as the study cohort as they formed the predominant dialysis group, comprising over $95 \%$ of the dialysis population at our centre. Diabetes mellitus was an exclusion in this study, so as to exclude the effects of diabetes on atherosclerosis. The study was approved by the Human Research Ethics Committee (HREC) of the University of the Witwatersrand, study number M160614. An interviewer-administered questionnaire was used to obtain information on participants' sociodemographic and cardiovascular risk factors including age, gender, waist-hip ratio (WHR), body mass index (BMI).

Waist and hip circumference and WHR were measured with patients in an erect position and after PD fluid had been drained out in CAPD patients. Weight was measured by using a weighing scale. In HD patients, the weight was obtained before initiation of dialysis and at the end of dialysis, however, the post-HD weight was used in analysis; weight was obtained in CAPD patients after the PD fluid was drained. Height was assessed by a stadiometer. Body mass index was calculated using the formula weight/height [2], while the body surface area was calculated using the Mosteller formula [16]. Three blood pressure readings were taken on the left arm with an appropriate sized cuff, $10 \mathrm{~min}$ apart, after the patient had rested for $5 \mathrm{~min}$ in a sitting position. The average of the last two readings was recorded as the blood pressure. Blood samples were taken before dialysis in HD patients. A serum lipogram (total cholesterol [TC], LDL-C, TG and HDL-C) was determined by an enzymatic colorimetric method using Roche cobas 8000 modular analyser series, module c701 analyzer (Roche, Japan). Lipoprotein ratios were calculated as follows: Atherogenic index of plasma $(\mathrm{AIP})=\log (\mathrm{Tg} / \mathrm{HDL}-\mathrm{C})$; Castelli index $1=\mathrm{TC} /$ HDL-C; Castelli index $2=\mathrm{LDL}-\mathrm{C} / \mathrm{HDL}-\mathrm{C}$; non-HDL- 
$\mathrm{C}=\mathrm{TC}-\mathrm{HDL}-\mathrm{C} ;$ Atherogenic index $(\mathrm{AI})=$ non-HDL-C $/$ HDL-C; Lipoprotein combined index $(\mathrm{LCI})=(\mathrm{TC} \times \mathrm{TG} \times$ LDL-C)/HDL-C [17]. Estimated GFR was calculated in controls and stage 3 CKD patients using the 2009 CKDEPI formula [18]. All participants had echocardiography and CIMT measurements in accordance with the guidelines of the American Society of Echocardiography [19], using a Philips iE33 echocardiography machine (Philips Corporation, USA). The CIMT measurement was done before initiation of HD in HD patients and after draining the abdomen in CAPD patients. Carotid intima media thickness was assessed using the vascular probe of the echocardiography machine, Philips iE33 (S5-1 probe) by focussing on the far wall of the carotid artery, $1 \mathrm{~cm}$ proximal to the dilatation of the carotid bulb along the long axis of the artery. Automatic echo-generated measurements with percentage quality of $95 \%$ were recorded. The procedure was carried out on both left and right carotid arteries and the average used in the analysis. Atherosclerotic vascular disease was defined by using a combination of increased CIMT $(>0.55 \mathrm{~mm})$ and presence of plaques.

\section{Power calculation and data analysis}

Stata version13.1 (StataCorp, USA) and IBM SPSS version 20 (IBM Corporation, Armonk, New York) were used for statistical analysis. The power to detect differences in levels of atherosclerosis was calculated. With a sample size of 40 in each group, a 5\% significance level and atherosclerosis proportion of $38.1 \%$ in haemodialysis patients compared to $7.93 \%$ in controls [8], there will be a power of 90.89 to detect differences in these groups.

Categorical variables were expressed as frequencies and percentages. Test of normality (Shapiro-Wilk) was performed on all continuous variables and data was presented as median and interquartile ranges (IQR). Comparison were performed between HD, CAPD, CKD patients and controls using the Kruskal-Wallis test and a post-hoc analysis was performed using the Dunn's test. Comparisons were made between those who had AsVD and those who did not, using the Wilcoxon rank-sum test.

Spearman correlation was used to determine the relationship between CIMT and cardiovascular risk factors among stage 3 CKD, CAPD, HD patients and the combination of the three groups. Multivariate regression analysis was performed to determine the relationship and contribution of cardiovascular risk factors to AsVD. The test of significance was taken as $p$-value $<0.05$. Post regression analysis was done to determine the goodness of fit of the regression model.

\section{Results}

The median age was 41 years (IQR 36.0-51.5) among stage 3 CKD patients, 39.5 years (IQR 35.0-46.5) among
CAPD patients, and 40.5 years (36.0-49.0) among HD patients; Table 1. Increased WHR was most prevalent among CAPD patients. Hypertension was most prevalent among HD patients, occurring in $82.5 \%(n=33 / 40)$ compared to $70 \%(n=28 / 40)$ in CAPD patients and $17.1 \%$ $(n=7 / 41)$ among controls; $(p<0.001)$. Total cholesterol was elevated in $52.5 \%(n=21 / 40)$ of CAPD patients compared to $22.5 \%(n=9 / 40)$ of CKD patients and $12.2 \%(n=$ $5 / 41)$ controls, $(p=0.006$ and $<0.001$ respectively); however, total cholesterol levels were not elevated in HD patients. Although the rate of statin use was higher among CAPD patients $(35 \%, 14 / 40)$ compared to the rate in HD patients, $(17.5 \%, n=7 / 40)$ there was no statistically significant difference, $\left(x^{2} 3.164, p\right.$ 0.075). Similarly, Angiotensin converting enzyme inhibitor (ACE-I) or Angiotensin receptor blocker (ARB) use was higher among PD patients compared to $\mathrm{HD}$ patients, however, not statistically significant, $\left(x^{2}\right.$ 0.621, $\mathrm{p}$ 0.432). Statin and ACE-I/ARB use were lowest among the stage 3 CKD patients. Atherosclerotic vascular disease was most prevalent among CAPD patients, occurring in $70 \%(n=28 / 40)$ and showed significant differences compared to $47.5 \%(n=19 / 40)$ among HD patients and $17.1 \%(n=7 / 41)$ among controls; $p=$ 0.041 and $<0.001$ respectively; Table 1 .

All tested cardiovascular risk factors showed significant differences between the four groups using the Kruskal-Wallis test, except for age and Atherosclerotic Index of Plasma (AIP). The Dunn's test result from a pairwise comparison showed that WHR, SBP, MABP, TC, LDL-C, non-HDL-C, LAD, EF, LVMI, CIMT, Castelli 1, AC, non-HDL-C were significantly increased among CAPD and HD patients compared to controls, while serum albumin and HDL-C were significantly decreased among CAPD and HD compared to controls, Table 2. Significantly higher serum phosphate levels and calcium-phosphate product $\left(\mathrm{CaXPO}_{4}\right)$ were present in CAPD patients when compared with controls [1.6 $(1.2-1.9)$ vs $1.0(0.9-1.1), p<0.001]$ and [40.1 (32.153.7) vs 29.5 (26.7-32.5), $\mathrm{p}<0.001$ ]; Table 2. Although serum levels of phosphate and $\mathrm{CaXPO}_{4}$ were higher among HD patients compared to controls, they were not statistically significant. $80 \%$ of CAPD and HD patients were on phosphate binders compared to $5 \%$ among the stage 3 CKD patients; the dialysate calcium was $1.75 \mathrm{mmol} / \mathrm{l}$ for CAPD and $1.5 \mathrm{mmol} / \mathrm{l}$ for $\mathrm{HD}$ patients.

Patients with AsVD were significantly older, and had increased WHR and LVMI, FRS and 10 year risk of developing CHD compared with those without AsVD. High density lipoprotein and left atrial diameter (LAD) showed a tendency towards significance when patients with AsVD were compared with patients without AsVD; Table 3. Higher values of CIMT and lower levels of serum albumin were seen in 
Table 1 Sociodemographic and clinical characteristics of the study population

\begin{tabular}{|c|c|c|c|c|}
\hline Parameter & CKD $(n=40)$ & CAPD $(n=40)$ & $\mathrm{HD}(n=40)$ & Controls $(n=41)$ \\
\hline Age & $41.0(36.0-51.5)$ & $39.5(35.0-46.5)$ & $40.5(36.0-49.0)$ & $41.0(29.0-48.0)$ \\
\hline DOD (years) & & $3.0(1.5-4.0)$ & $3.0(2.0-6.5)$ & \\
\hline \multicolumn{5}{|l|}{ Gender (n/\%) } \\
\hline Female & $20(50.0)$ & $19(47.5)$ & $18(45.0)$ & $23(56.1)$ \\
\hline Male & $20(50.0)$ & $21(52.5)$ & $22(55.0)$ & $18(43.9)$ \\
\hline \multicolumn{5}{|l|}{ BMl } \\
\hline$<30 \mathrm{~kg} / \mathrm{m}^{2}$ & $19(47.5)$ & $31(77.5)$ & $32(80.0)$ & $25(61.0)$ \\
\hline$>30 \mathrm{~kg} / \mathrm{m}^{2}$ & $21(52.5)$ & $9(22.5)$ & $8(20.0)$ & $16(39.0)$ \\
\hline \multicolumn{5}{|l|}{ WHR } \\
\hline Normal & $12(30.0)$ & $9(22.5)$ & $15(37.5)$ & $28(68.3)$ \\
\hline Increased & $28(70.0)$ & $31(72.5)$ & $25(62.5)$ & $13(31.7)$ \\
\hline \multicolumn{5}{|l|}{ Hypertension $^{a}$} \\
\hline Absent & $15(37.5)$ & $12(30)$ & $17(17.5)$ & $34(82.9)$ \\
\hline Present & $25(62.5)$ & $28(70)$ & $33(82.5)$ & $7(17.1)$ \\
\hline $\mathrm{SCr}(\mu \mathrm{mol} / \mathrm{l})$ & $124(106-166)$ & 1175 (878-1345) & $513(405-712$ & 80 (63-89) \\
\hline Albumin (g/l) & $41.5(38.5-44.0)$ & $35.5(33.0-40.0)$ & $38.5(35.0-41.0)$ & $44.0(42.0-45.0)$ \\
\hline \multicolumn{5}{|l|}{ TC (mmol/l) } \\
\hline$<5.17$ & $31(77.5)$ & $19(47.5)$ & $40(100)$ & $36(87.8)$ \\
\hline$>5.17$ & $9(22.5)$ & $21(52.5)$ & 0 & $5(12.2)$ \\
\hline \multicolumn{5}{|l|}{ LDL } \\
\hline$<2.59$ & $19(47.5)$ & $14(35.0)$ & $36(90.0)$ & $21(51.2)$ \\
\hline$>2.59$ & $21(52.5)$ & $26(65.0)$ & $4(10.0)$ & $20(48.8)$ \\
\hline \multicolumn{5}{|l|}{$\mathrm{HDL}^{\mathrm{b}}$} \\
\hline Low & $30(75.0)$ & $21(52.5)$ & $15(37.5)$ & $23(56.1)$ \\
\hline Normal & $10(25.0)$ & $19(47.5)$ & $25(62.5)$ & $18(43.9)$ \\
\hline \multicolumn{5}{|l|}{ SU (n/\%) } \\
\hline Yes & $7(17.5)$ & $14(35.0)$ & $7(17.5)$ & \\
\hline No & $33(82.5)$ & $26(65.0)$ & $33(82.5)$ & \\
\hline \multicolumn{5}{|l|}{ AAU (n/\%) } \\
\hline Yes & $7(17.5)$ & $11(27.5)$ & $8(20.0)$ & \\
\hline No & $33(82.5)$ & $29(72.5)$ & $32(80.0)$ & \\
\hline \multicolumn{5}{|l|}{ PBU (n/\%) } \\
\hline Yes & $2(5.0)$ & $32(80.0)$ & $32(80.0)$ & \\
\hline No & $38(95.0)$ & $8(20.0)$ & $8(20.0)$ & \\
\hline \multicolumn{5}{|l|}{ AsVD (n/\%) } \\
\hline Absent & $21(52.5)$ & $12(30.0)$ & $21(52.5)$ & 34 (82.9) \\
\hline Present & $19(47.5)$ & $28(70.0)$ & $19(47.5)$ & $7(17.1)$ \\
\hline
\end{tabular}

CKD Chronic kidney disease, PD Peritoneal dialysis, HD Haemodialysis, DOD Duration on dialysis, BMI Body mass index, WHR Waist-hip ratio, TC Total cholesterol, LDL-C Low density cholesterol, HDL-C High density cholesterol, SU Statin use, AAU ACE-I / ARB (angiotensin converting enzyme / angiotensin receptor blocker) use, PBU Phosphate binder use (calcium carbonate), AsVD Atherosclerotic vascular disease; ${ }^{a}$ Systolic blood pressure $>140 \mathrm{mmHg} \pm$ diastolic blood pressure $>90 \mathrm{mmHg}$, Low $\mathrm{HDL}-\mathrm{C}=<1.03$ in male and $<1.29 \mathrm{mmol} / \mathrm{l}$ in female

CAPD patients compared to the other study groups;

Fig. 1.

CIMT correlated with age in all the kidney disease groups with the strongest association seen in CKD patients $(r=0.48$, $p=0.002$; Spearman correlation). A moderate positive correlation was observed between CIMT and LVMI across all kidney disease groups. There was a negative correlation between CIMT and Castelli indices $1 \& 2$ and AC among HD patients, $(\mathrm{r}=-0.43,0.006 ; \mathrm{r}=-0.44, p=0.004 ; \mathrm{r}=-0.43, p=$ 0.006; respectively). There was no correlation between CIMT 
Table 2 Comparison of clinical characteristics and echocardiographic parameters among chronic kidney disease, haemodialysis, peritoneal dialysis patients and controls

\begin{tabular}{|c|c|c|c|c|c|c|}
\hline \multirow[t]{2}{*}{ Parameter } & \multirow{2}{*}{$\begin{array}{l}\text { K-W test } \\
(n=161) x^{2}(p \text {-value })\end{array}$} & \multicolumn{5}{|c|}{ Dunn test ( $p$-value) } \\
\hline & & CKD/controls & CAPD/controls & $\mathrm{HD} /$ controls & CKD/CAPD & $\mathrm{CKD} / \mathrm{HD}$ \\
\hline Age (years) & $1.38(0.71)$ & & & & & \\
\hline BMI Kg/m² & $16.3(0.001)$ & 0.077 & 0.312 & 0.086 & 0.001 & 0.001 \\
\hline WHR & $20.6(<0.001)$ & 0.001 & $<0.001$ & 0.020 & 0.758 & 0.310 \\
\hline $\mathrm{SBP}(\mathrm{mmHg})$ & $39.1(<0.001)$ & $<0.001$ & $<0.001$ & $<0.001$ & 0.263 & 0.025 \\
\hline MABP $(\mathrm{mmHg})$ & $89.1(<0.001)$ & $<0.001$ & $<0.001$ & $<0.001$ & 0.073 & 0.007 \\
\hline $\mathrm{TC}(\mathrm{mmol} / \mathrm{l})$ & $50.6(<0.001)$ & 0.019 & 0.005 & $<0.001$ & 0.007 & 0.001 \\
\hline $\mathrm{TG}(\mathrm{mmol} / \mathrm{l})$ & $14.0(0.003)$ & 0.427 & 0.570 & $<0.001$ & 0.820 & 0.005 \\
\hline LDL-C (mmol/l) & $35.9(<0.001)$ & 0.585 & 0.003 & $<0.001$ & 0.005 & $<0.001$ \\
\hline $\mathrm{HDL}-\mathrm{C}(\mathrm{mmol} / \mathrm{l})$ & $10.6(0.014)$ & 0.001 & $<0.001$ & $<0.001$ & 0.592 & 0.152 \\
\hline Castelli1 & $12.4(0.006)$ & 0.966 & 0.030 & 0.436 & 0.008 & 0.256 \\
\hline Castelli2 & $10.9(0.012)$ & 0.261 & 0.249 & 0.085 & 0.011 & 0.373 \\
\hline$A C$ & $12.4(0.006)$ & 0.966 & 0.030 & 0.436 & 0.008 & 0.256 \\
\hline AIP & $3.3(0.354)$ & & & & & \\
\hline non-HDL-C & $39.8(<0.001)$ & 0.308 & $<0.001$ & 0.001 & 0.008 & $<0.001$ \\
\hline eGFR $\left(\mathrm{ml} / \mathrm{min} / 1.73 \mathrm{~m}^{2}\right)$ & $144.0(<0.001)$ & $<0.001$ & & & & \\
\hline Calcium (mmol/l) & $8.3(0.041)$ & 0.974 & 0.034 & 0.072 & 0.033 & 0.145 \\
\hline Phosphate (mmol/l) & $35.7(<0.001)$ & 0.006 & 0.058 & 0.352 & $<0.001$ & 0.060 \\
\hline $\mathrm{CaXPO}_{4}\left(\mathrm{mg}^{2} / \mathrm{dl}^{2}\right)$ & $22.2(<0.001)$ & 0.132 & $<0.001$ & 0.228 & $<0.001$ & 0.755 \\
\hline Albumin(g/l) & $47.4(<0.001)$ & 0.031 & $<0.001$ & $<0.001$ & $<0.001$ & 0.043 \\
\hline LAD & $96.4(<0.001)$ & $<0.001$ & $<0.001$ & $<0.001$ & 0.692 & 0.010 \\
\hline EF (\%) & $32.3(<0.001)$ & $<0.001$ & 0.001 & 0.001 & 0.823 & 0.116 \\
\hline LVMI $\left(\mathrm{g} / \mathrm{m}^{2}\right)$ & $24.2(<0.001)$ & 0.136 & $<0.001$ & $<0.001$ & 0.027 & 0.034 \\
\hline FRS & $13.1(0.004)$ & 0.035 & 0.005 & 0.913 & 0.178 & 0.074 \\
\hline Risk of CHD (\%) & $10.3(0.017)$ & 0.218 & 0.034 & 0.678 & 0.371 & 0.104 \\
\hline CIMT (mm) & $36.3(<0.001)$ & $<0.001$ & $<0.001$ & $<0.001$ & 0.012 & 0.673 \\
\hline
\end{tabular}

$B M I$ Body mass index, WHR Waist-hip ratio, SBP Systolic blood pressure, MABP Mean arterial blood pressure, TC Total cholesterol, TG Triglyceride, $L D L$ Low density lipoprotein, HDL High density lipoprotein, AC Atherogenic coefficient, AIP Atherogenic index of plasma non-HDL - non high density lipoprotein eGFR - estimated glomerular filtration rate, $L A D$ Left atrial diameter, EF Ejection fraction, $L V M$ Left ventricular mass, LVMI Left ventricular mass index, FRS Framingham risk score; Risk of CHD - 10-year risk of coronary heart disease

and lipoprotein ratios in stage $3 \mathrm{CKD}$ and CAPD patients, and when all the kidney disease groups were combined; Table 4.

Binary logistic regression analysis showed that age and $\mathrm{LVH}$ were independent predictors of AsVD in dialysis patients after adjusting for gender, hypertension, TC and LDL-C and TG; Table 5.

\section{Discussion}

Carotid intima media thickness is a reliable surrogate marker of subclinical atherosclerosis in the general population and increased CIMT has been associated with increased risk of cardiovascular events [20]. Similar findings have been reported among CKD and ESKD patients [21]. Our study showed a significantly higher prevalence of AsVD among CKD, CAPD and HD patients compared to controls. Almost three-quarters of the CAPD patients and almost half of the CKD and HD patients had AsVD compared to less than one-fifth of the control group. This is consistent with results from previous studies $[8,9]$. The presence of AsVD in $17.1 \%$ of the controls in our study is comparable to the prevalence of $29.3 \%$ for peripheral arterial disease found among black rural dwellers in South Africa [22]; the lower prevalence observed in our study may be due to the exclusion of elderly people and diabetics from our study. Although the finding of high prevalence of AsVD in our stage 3 CKD and HD groups can be explained by the high prevalence of cardiovascular risk factors such as hypertension and reduced renal function among the kidney disease groups, we suggest that the very high prevalence of AsVD seen in CAPD may be associated with 
Table 3 Comparison between those who had atherosclerotic vascular disease and those without atherosclerotic vascular disease among kidney disease patients

\begin{tabular}{|c|c|c|c|}
\hline Risk factors & AsVD present $(n=66)$ & AsVD Absent $(n=54)$ & $p$-value \\
\hline Age & $43.5(36.0-50.0)$ & $37.0(30.0-44.0)$ & $0.002^{*}$ \\
\hline BMI & $27.0(22.5-31.9)$ & $26.4(22.0-30.5)$ & 0.394 \\
\hline WHR & $0.92(0.88-0.96)$ & $0.89(0.85-0.94)$ & $0.028^{*}$ \\
\hline SBP & 148.5 (131.0-164.0) & $147.0(127-167)$ & 0.411 \\
\hline MABP & 139.8 (116.3-161.0) & $141.8(130.3-155.3)$ & 0.792 \\
\hline TC & $4.4(3.4-5.3)$ & $4.1(3.5-4.7)$ & 0.342 \\
\hline TG & $1.2(0.8-1.6)$ & $1.3(0.7-1.8)$ & 0.444 \\
\hline LDL & $2.5(1.7-3.3)$ & $2.3(1.8-2.7)$ & 0.150 \\
\hline $\mathrm{HDL}$ & $1.2(1.0-1.4)$ & $1.1(0.9-1.4)$ & 0.065 \\
\hline Castelli1 & $3.5(2.8-4.4)$ & $3.6(3.1-4.6)$ & 0.560 \\
\hline Castelli2 & $1.9(1.5-2.9)$ & $2.0(1.6-2.6)$ & 0.914 \\
\hline$A C$ & $2.5(1.8-3.4)$ & $2.6(2.1-3.6)$ & 0.560 \\
\hline AIP & $0.0(-0.5-0.4)$ & $0.1(-0.4-0.4)$ & 0.202 \\
\hline non-HDL & $3.2(2.3-4.1)$ & $3.0(2.5-3.3)$ & 0.518 \\
\hline $\mathrm{LCl}$ & $9.5(4.8-21.7)$ & $10.1(4.8-18.3)$ & 0.868 \\
\hline $\mathrm{EF}$ & $58.5(53.0-64.0)$ & $61.0(56.0-64.0)$ & 0.257 \\
\hline LAD & $3.9(3.5-4.5)$ & $3.8(3.2-4.2)$ & 0.050 \\
\hline LVMI & $122.9(103.5-146.0)$ & $98.6(83.0-117.1)$ & $<0.001^{*}$ \\
\hline FRS & $7.5(3.0-11.0)$ & $5(0-9.0)$ & 0.036 \\
\hline Risk of CHD (\%) & $2.0(1.0-5.0)$ & $0.8(0.5-1.0)$ & $<0.001^{*}$ \\
\hline
\end{tabular}

* - statistically significant, $p<0.05$, AsVD Atherosclerotic vascular disease, BMI Body mass index, WHR Waist-hip ratio, SBP Systolic blood pressure, MABP Mean arterial blood pressure, TC Total cholesterol, TG Triglyceride, LDL-C Low density lipoprotein, $H D L-C$ High density lipoprotein, $S C r$ Serum creatinine, eGFR Estimated glomerular filtration rate, $\mathrm{CaXPO}_{4}$ Calcium-phosphate product, $A C$ Atherogenic coefficient, AIP Atherogenic index of plasma, non-HDL-C- nonhigh density lipoprotein, $L C l$ Lipoprotein combine index, EF Ejection fraction, $L A D$ Left atrial diameter, $L V M$ Left ventricular mass, $L V M I$ Left ventricular mass index, FRS Framingham risk score, Risk of CHD - 10-year risk of coronary heart disease

additional CAPD-related factors. Firstly, synergistic interplay between high glucose exposure and inflammation may contribute to the high prevalence of AsVD among CAPD patients [23, 24]. Exposure of CAPD patients to high glucose concentrations via the use of glucose-containing PD fluids, in the presence of high levels of inflammation, could result in increased glucose absorption and consequent hyperinsulinaemia, which has been associated with hypertension, obesity, dyslipidaemia and glucose intolerance [25]. In the setting of chronic hyperinsulinaemia, experimental evidence supports marked increase in lipogenesis in white adipose tissue and the liver [26]. From our study, the finding of higher prevalence of increased TC and LDL-C among CAPD patients compared to stage 3 CKD and HD patients further indicates the possibility of hyperinsulinaemia among PD patients. Secondly, we found significantly higher levels of uraemic retention solutes such as serum creatinine and urea among CAPD patients compared to $\mathrm{HD}$ and stage $3 \mathrm{CKD}$ patients. In comparison to CAPD patients, the lower levels of uraemic retention solutes in HD patients, seen in our study may be explained by the effectiveness of current HD procedures in the clearance of uraemic toxins using biocompatible membranes, high flux dialyzers, dialysate flow rate of $500 \mathrm{ml} / \mathrm{min}$ and moderate blood flow rate of $350 \mathrm{ml} /$ min, with dialysis undertaken thrice weekly and four hours per session. However, CAPD patients were dialysing at home and the prescribed dose of PD may not have been delivered due to incomplete adherence to treatment at home; a higher dialysis dose of PD than that delivered may have been required. In addition, the CAPD patients recruited into our study used conventional (glucose-based) PD fluids, which is acidic and contains supra-physiologic levels of lactate and a high glucoseinduced osmolality of $395 \mathrm{mOsm} / \mathrm{Kg} \mathrm{H}_{2} 0$; this could have contributed to inflammation and worsening overall cardiovascular risk in this group of PD patients. Thirdly, higher uraemic retention solutes among CAPD patients may likely connote the presence of high levels of uraemic toxins such as middle molecules and proteinbound solutes among the CAPD patients which have been associated with CVD [27-29]. In our study, the median duration on CAPD was three years, therefore, loss of residual renal function in this group of patients, typically seen from three years after commencement of $\mathrm{PD}$, could have contributed to the high levels of uraemic toxins. Bammens et $\mathrm{al}^{27}$ found that increasing PD dose may compensate for declining residual renal function by increasing elimination of water soluble uraemic solutes but not middle molecules like p-cresol. Several studies have demonstrated an association between uraemic toxins (such as indoxyl sulphate, p-cresyl sulphate) and CVD $[28,29]$. Both total and free indoxyl sulphate and p-cresyl sulphate were found to be independently associated with structural and functional markers of CVD [29]. Further studies on the relationship of chronic inflammation and uraemic toxins to AsVD in ESKD among black Africans will be required to establish this association. Serum levels of phosphate and calcium/ phosphate product were higher among kidney disease patients with AsVD compared to patients without AsVD, but were not statistically significant, possibly because about $80 \%$ of ESKD patients were on phosphate binders and vitamin D.

Statistically significant differences were found in clinical and echocardiographic risk factors when each of the kidney disease groups was compared with controls. Of particular importance were systolic blood pressure (SBP), mean arterial blood pressure (MABP), WHR, non-HDL-C cholesterol, LAD, LVMI and CIMT which showed a near consistent $p$ value of $<0.001$ when the 


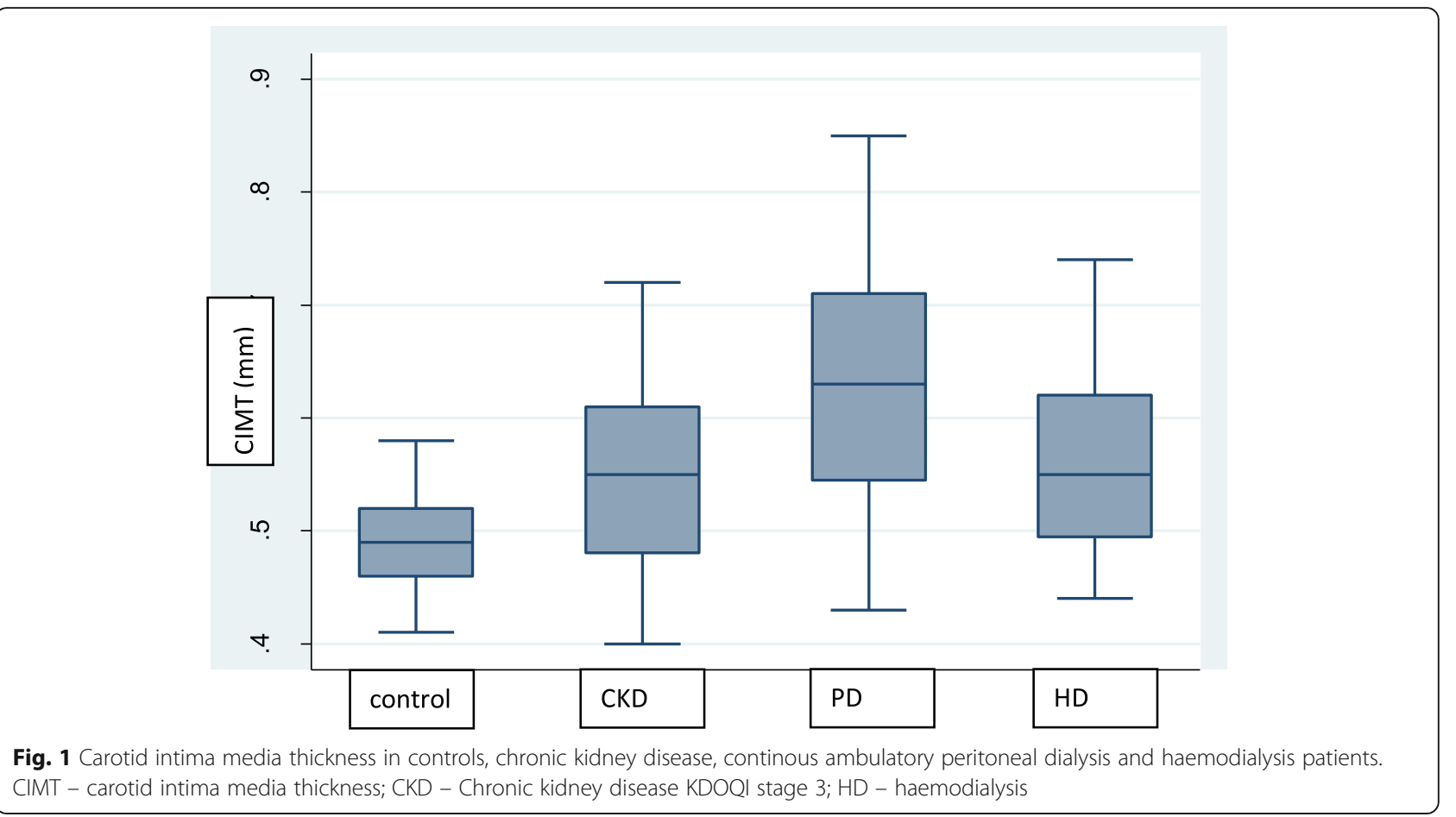

Table 4 Correlation between carotid intima media thickness and risk factors for cardiovascular disease among chronic kidney disease, peritoneal dialysis and haemodialysis patients

\begin{tabular}{|c|c|c|c|c|}
\hline Parameter & CKD $(n=40)$ rho ( $p$-value) & CAPD $(n=40)$ rho (p-value) & HD $(n=40)$ rho (p-value) & TOTAL $(n=120)$ rho ( $p$-value) \\
\hline Age & $0.48(0.002)$ & $0.28(0.077)$ & $0.27(0.099)$ & $0.33(<0.001)$ \\
\hline $\mathrm{BMI}$ & $0.21(0.205)$ & $0.10(0.538)$ & $0.03(0.845)$ & $0.04(0.651)$ \\
\hline WHR & $0.36(0.023)$ & $0.31(0.051)$ & $0.13(0.429)$ & $0.27(0.003)$ \\
\hline SBP & $0.16(0.318)$ & $0.21(0.187)$ & $-0.09(0.579)$ & $0.12(0.187)$ \\
\hline $\mathrm{TC}$ & $-0.05(0.760)$ & $-0.04(0.834)$ & $-0.13(0.428)$ & $0.08(0.411)$ \\
\hline $\mathrm{TG}$ & $-0.19(0.240)$ & $-0.07(0.681)$ & $-0.03(0.845)$ & $-0.05(0.606)$ \\
\hline LDL & $0.19(0.244)$ & $0.11(0.501)$ & $-0.33(0.040)$ & $0.13(0.173)$ \\
\hline $\mathrm{HDL}$ & $-0.29(0.069)$ & $0.17(0.291)$ & $0.48(0.002)$ & $0.14(0.130)$ \\
\hline Castelli1 & $0.16(0.322)$ & $-0.19(0.238)$ & $-0.43(0.006)$ & $-0.06(0.500)$ \\
\hline Castelli2 & $0.19(0.245)$ & $-0.07(0.662)$ & $-0.44(0.004)$ & $-0.03(0.772)$ \\
\hline$A C$ & $0.16(0.322)$ & $-0.19(0.238)$ & $-0.43(0.006)$ & $-0.06(0.500)$ \\
\hline AIP & $-0.01(0.955)$ & $-0.14(0.383)$ & $-0.20(0.219)$ & - $0.09(0.349)$ \\
\hline non-HDL & $0.09(0.574)$ & $-0.11(0.500)$ & $-0.29(0.070)$ & $0.04(0.662)$ \\
\hline $\mathrm{LCl}$ & $0.04(0.824)$ & $-0.10(0.557)$ & $-0.20(0.219)$ & $0.01(0.893)$ \\
\hline Calcium (mmol/l) & $-0.12(0.456)$ & $-0.02(0.889)$ & $-0.09(0.556)$ & $-0.12(0.184)$ \\
\hline Phos. (mmol/l) & $0.00(0.982)$ & $0.09(0.602)$ & $-0.13(0.425)$ & $0.10(0.277)$ \\
\hline $\mathrm{CaXPO}_{4}\left(\mathrm{mg}^{2} / \mathrm{dl}^{2}\right)$ & $-0.02(0.898)$ & $0.05(0.749)$ & $-0.13(0.425)$ & $0.06(0.508)$ \\
\hline EF & $-0.19(0.230)$ & $-0.01(0.930)$ & $0.01(0.893)$ & $-0.11(0.244)$ \\
\hline LAD & $0.20(0.217)$ & $0.55(<0.001)$ & $-0.17(0.300)$ & $0.21(0.025)$ \\
\hline LVMI & $0.40(0.012)$ & $0.42(0.006)$ & $0.44(0.005)$ & $0.43(<0.001)$ \\
\hline
\end{tabular}

CKD Chronic kidney disease, CAPD Continuous ambulatory peritoneal dialysis, HD Haemodialysis, BMI Body mass index, WHR Waist-hip ratio, SBP Systolic blood pressure, MABP Mean arterial blood pressure, TC Total cholesterol, TG Triglyceride, LDL Low density lipoprotein, HDL High density lipoprotein, eGFR Estimated glomerular filtration rate, $A C$ Atherogenic coefficient, AIP Atherogenic index of plasma; non-HDL- non- high density lipoprotein; $L C I$ Lipoprotein combine index, Phos Phosphate, $\mathrm{CaXPO}_{4}$ Calcium-phosphate product, EF Ejection fraction, LAD Left atrial diameter, LVM Left ventricular mass, LVMI Left ventricular mass index 
Table 5 Relationship between atherosclerotic vascular disease and risk factors for cardiovascular disease among dialysis patients

\begin{tabular}{llll}
\hline Risk factors & OR & $95 \% \mathrm{Cl}(n=80)$ & $p$-value \\
\hline Age $(>$ 40 years) & 3.11 & $1.00-9.65$ & $0.049^{*}$ \\
Gender & 1.58 & $0.48-5.20$ & 0.453 \\
Hypertension $^{\mathrm{a}}$ & 1.49 & $0.37-5.97$ & 0.575 \\
LVH & 49.79 & $2.58-959.68$ & $0.010^{*}$ \\
TC $(>5.17 \mathrm{mmol} / \mathrm{l})$ & 12.15 & $0.98-150.60$ & 0.052 \\
LDL-C (> 2.59 mmol/l) & 1.64 & $0.34-7.99$ & 0.541 \\
TG (> 1.69 mmol/l) & 0.69 & $0.17-2.80$ & 0.599 \\
\hline
\end{tabular}

* - Statistically significant, $p<0.05$; LVH - left ventricular hypertrophy, TC Total cholesterol, LDL-C - low density lipoprotein, BMI Body mass index; ${ }^{a}$ systolic hypertension (systolic blood pressure $>140 \mathrm{mmHg}$ )

kidney disease groups were compared with controls. These findings were consistent with those documented in previous studies designed to evaluate the CVD risk factors in CKD [30, 31].

When patients who had AsVD were compared with those who did not, they were significantly older and had increased WHR and LVMI. The association between age and AsVD in our study is consistent with previous observations [32] and could be due to the fact that advancing age is associated with known cardiovascular risk factors such as hypertension, diabetes and vascular disease [33]. In addition, advancing age predisposes to endothelial dysfunction [34]. The finding of a significantly higher LVMI among patients who had AsVD and an association between AsVD and LVH among kidney disease patients is consistent with a previous study [35]. In addition to being categorised as a CVD, LVH has been shown as a cardiovascular risk factor in the general population [36] and in ESKD patients [37]. A significantly higher frequency of LVH was reported among black South African ESKD patients on HD compared to controls [8]. In the presence of hypertension and renal dysfunction, pressure and volume overload causes the cardiac myocytes to undergo conformational changes in order to compensate for haemodynamic alterations, resulting in LVH [38]. We found no significant difference in the 10-year risk of developing CHD when kidney disease patients were compared with controls, except in CAPD patients. Similarly, approximately $85 \%$ of kidney disease patients in each group were classified as low risk. These findings support the available evidence that the Framingham risk assessment for $\mathrm{CHD}$ has a poor predictive value for CHD among CKD patients [39]. In addition, the Framingham score does not consider the CKD-related risk factors for CVD, limiting its use in CKD patients [40]. On multiple comparisons between the four groups studied, significantly higher Framingham risk score and the 10-year risk of developing CHD were seen in CAPD patients when compared with controls and HD patients; these findings corroborates the higher carotid atherosclerotic burden seen in CAPD patients compared to HD patients in this study. The finding of significantly increased 10-year risk of developing CHD among kidney disease patients who had AsVD compared to those who do not have AsVD suggests that the Framingham tool may have a more useful discriminant role for CHD among CKD patients who have AsVD, compared to the predictive role for CHD seen in a nonCKD population. We recommend that a larger study will be helpful in confirming this finding.

Age (> 40 years) and LVH independently predicted AsVD among ESKD patients after adjusting for gender, WHR, systolic hypertension, LDL-C and TG. We found that LVH confers a 49-fold risk of AsVD among our ESKD patients. This highlights the robust relationship between LVH and AsVD among our ESKD group and underscores the importance of $\mathrm{LVH}$ as a CVD risk factor and the need to direct treatment strategies towards $\mathrm{LVH}$ reduction among CKD patients.

We recommend that longitudinal follow-up studies with a larger study population be designed to evaluate the relationship of AsVD to inflammation, hyperinsulinaemia and uraemic toxins, especially middle molecules, among black ESKD patients on CAPD and HD to ascertain the contribution of these risk factors to AsVD. We further recommend a randomised controlled trial among CAPD patients comparing CAPD patients using conventional PD fluids with patients using biocompatible PD fluids to determine the difference in CVD burden, if any, in both groups. However, while awaiting the outcomes from a randomised trial, we believe that patients using more biocompatible PD fluids may have a reduced CVD burden; therefore, it should be made more readily available and affordable.

This study has some limitations. While the study was adequately powered, the sample size is relatively small. We did not assess serum concentration of insulin and insulin resistance in these patients; these could have helped to confirm hyperinsulinaemia as a risk factor for AsVD among CAPD patients. The kt/V was also not documented, and this may have helped in objective assessment of adequacy of dialysis. The exclusion of the elderly, due to the relatively young age of the dialysis population at our centre, from this study could have reduced the overall prevalence of AsVD in the different patient groups investigated. Some of the patients recruited were on statins, this may have influenced the prevalence of AsVD reported in this study. The cross-sectional nature of this study allowed for measurements of the various parameters at a single point; a longitudinal study will provide data on the evolution of atherosclerosis over the period of CKD and dialysis. 


\section{Conclusion}

We found that AsVD was more prevalent among CAPD patients compared to pre-dialysis CKD and HD patients. Among all lipoprotein ratios assessed, non-HDL-C showed the most consistent significant difference between the groups. There was an association between AsVD and age, WHR and LVMI. Age (> 40 years) and presence of LVH independently predicted AsVD. The use of conventional PD fluids could have contributed to the higher prevalence of AsVD among CAPD patients; therefore, we advocate for improved accessibility and affordability of biocompatible PD fluids.

\begin{abstract}
Abbreviations
Al: Atherogenic index; AIP: Atherogenic index of plasma; AsVD: Atherosclerotic vascular disease; BMI: Body mass index; CAPD: Continuous ambulatory peritoneal dialysis; CIMT: Carotid intima media thickness; CKD: Chronic kidney disease; eGFR: Estimated glomerular filtration rate; ESKD: End-stage kidney disease; HD: Haemodialysis; HDL-C: High density lipoprotein; LDL-C: Low density lipoprotein; LVMI: Left ventricular mass index; non-HDL: Non-high density lipoprotein; PD: Peritoneal dialysis; SCr: Serum creatinine; TC: Total cholesterol; TG: Triglycerides; WHR: Waist-hip ratio
\end{abstract}

\section{Acknowledgements}

This work was made possible by the ISN fellowship granted to Dr. S.O.Oguntola to study at the Charlotte Maxeke Johannesburg Academic Hospital, University of the Witwatersrand, Johannesburg, South Africa. The authors wish to express their appreciation to Jamie Leigh-Hayes for her assistance during data collection.

\section{Ethics approval and consent to participate in the study}

This study was approved by the Human Research and Ethics Committee (HREC) of the.

University of the Witwatersrand, Johannesburg, South Africa; clearance certificate number M160614. All participants' gave written informed consent before enrolment.

\section{Availability of data or materials}

The dataset used in the analysis is available with the corresponding author and will be released on request.

\section{Authors' contributions}

$\mathrm{SOO}, \mathrm{MOH}, \mathrm{RD}$ and $\mathrm{SN}$ were involved in study design. Protocol writing, review and amendments were done by SOO, MOH, RD, AV, PM and SN. SOO, $\mathrm{MOH}, \mathrm{RD}, \mathrm{AV}, \mathrm{PM}, \mathrm{RD}$ and $\mathrm{SN}$ participated in data collection. RD was involved in laboratory analysis of samples. Data analysis was done by SOO, $\mathrm{MOH}, \mathrm{AV}, \mathrm{PM}$ and SN. First draft of manuscript was prepared by SOO, all authors reviewed and approved the manuscript.

\section{Funding}

This study was financed through research grants to the Supervisors (SN and RD) by the National Research Foundation of South Africa.

\section{Consent for publication}

All the authors gave their consent for the publication of this article.

\section{Competing interests}

There is no financial or non-financial competing interests.

\section{Author details}

${ }^{1}$ Department of Internal Medicine, Division of Nephrology, Faculty of Health Sciences, University of Witwatersrand, 7, York Street, Parktown, Johannesburg, South Africa. ${ }^{2}$ Department of Internal Medicine, Division of Cardiology, Faculty of Health Sciences, University of Witwatersrand, Johannesburg, South Africa. ${ }^{3}$ Department of Internal Medicine Laboratory, Faculty of Health Sciences, University of Witwatersrand, Johannesburg, South Africa. ${ }^{4}$ Department of Internal Medicine, Ladoke Akintola University of Technology Teaching Hospital, Osogbo, Osun-State, Nigeria.
Received: 13 February 2018 Accepted: 9 October 2019

Published online: 30 October 2019

\section{References}

1. National Kidney Foundation. K/DOQI clinical practice guidelines for chronic kidney disease: evaluation, classification and stratification. Am J Kid. Dis. 2002; 39(suppl 1): S1-S266.

2. Collins AJ, Li S, Gilbertson DT, Liu J, Chen SC, Herzog CA. Chronic kidney disease and cardiovascular disease in the medicare population. Kidney Int Suppl. 2003;87:S24-31.

3. Lindner A, Charra B, Sherrard DJ, Scribner BH. Accelerated atherosclerosis in prolonged maintenance hemodialysis. New Eng J Med. 1974;290:697-701.

4. Rahman M, Brown CD, Coresh J, Davis BR, Eckfeldt J, Kopyt N, et al. The prevalence of reduced glomerular filtration rate in older hypertensive patients and its association with cardiovascular disease: a report from the anti-hypertensive and lipid-lowering treatment to prevent heart attack trial. Arch Intern Med. 2004;164(9):969-76.

5. Lash JP, Go AS, Appel L, He J, Ojo A, Rahman M, et al. Chronic renal insufficiency cohort (CRIC) study: baseline characteristics and associations with kidney function. Clin J Am Soc Nephrol. 2009;4:1302-11.

6. Matsushita K, Kwak L, Sang Y, Ballew SH, Skali H, Shah AM, et al. Kidney disease measures and left ventricular structure and function: the atherosclerosis risk in communities' study. J Am Heart Assoc. 2017;6: e006259. https://doi.org/10.1161/JAHA.117.006259.

7. Kaze FF, Kengne A, Djalloh AA, Ashuntantang G, Halle MP, Menanga AP, et al. Pattern and correlates of cardiac lesions in a group of sub-Saharan African patients on maintenance haemodialysis. Pan African Medical Journal. 2014; 17: 03 doi: https://doi.org/10.11604/pamj.2014.17.3.3422

8. Amira OC, Naicker S, Manga P, Sliwa K, Mia A, Raal F, et al. Adiponectin and atherosclerosis risk factors in African haemodialysis patients: a population at low risk for atherosclerotic cardiovascular disease. Hemodialysis Int. 2012; 16(1):59-68.

9. Freercks R, Swanepoel C, Carrara H, Moosa S, Lachman A, Rayner B. Vascular calcification in south African dialysis patients: ethnic variation, prevalence, detection and haemodynamic correlates. Nephrology. 2012;17:607-15.

10. Szeto CC, Wong TY, Chow KM, Leung CB, Li PK. Are peritoneal dialysis patients with and without residual renal function equivalent for survival? Insight from a retrospective review of the cause of death. Nephrol Dial Transplant. 2003;18:977-82.

11. Tamayo-Isla RA, Ameh O, Mapiye D, Swanepoel CR, Bello AK, Ratsela AR, et al. Baseline predictors of mortality among predominantly rural dwelling end-stage renal disease patients on chronic dialysis therapies in Limpopo. South Africa PLoS ONE. 2016;11(6):e0156642. https://doi.org/10.1371/journal. pone.0156642.

12. Schuchardt M, Tolle M, Van der Giet M. High density lipoprotein structural and functional changes under uraemic conditions and the therapeutic consequences. Handb Exp Pharmacol. 2015;224:423-53.

13. Norman R, Bradshaw D, Steyn K, Gaziano T. The south African comparative risk assessment collaborating group. Estimating the burden of disease attributable to high cholesterol in South Africa in 2000. S Afr Med J. 2007: 97(8):708-15.

14. Shurraw S, Tonelli M. Statin for treatment of dyslipidaemia in chronic kidney disease. Perit Dial Int. 2006;26:523-39.

15. Moberly JB, Attman PO, Samuelsson O, Johansson AC, Knight-Gibson AP. Alteration in lipoprotein composition in peritoneal dialysis patients. Perit Dial Int. 2002;22:L220-8.

16. Mosteller RD. Simplified calculation of body surface area. N Engl J Med. 1987;317(17):1098

17. Cai G, Ganwei S, Sheliang X, Wei L. The atherogenic index is a strong and independent predictor for coronary artery disease in the Chinese Han population. Medicine 2017; 96: 37(e8058).

18. Early A, Miskulin D, Lamb EJ, Levey AS, Uhliq K. Estimating equations for glomerular filtration rate in the era of creatinine standardization. A systematic review. Ann Intern Med. 2012;156:785-95.

19. Lang RM, Bierig M, Devereux RB, Flachskampf FA, Foster E, Pellikka PA, et al. Recommendations for cardiac quantification. A report from the American Society of Echocardiography's guidelines and standard committee and the chamber quantification writing group, developed in conjunction with the European association of echocardiography, a branch of the European association of cardiology. J Am Soc Echocardiogr. 2005;18:1440-63. 
20. Bots ML, Hoes AW, Koudstaal PJ, Hofman A, Grobbee DE. Common carotid intima-media thickness and risk of stroke and myocardial infarction. Circulation. 1997;96:1432-7.

21. Adeseun GA, Xie D, Wang X, Joffe MM, Mohler ER, Townsend RR, et al. Carotid plaque, carotid intima-media thickness and coronary calcification equally discriminate prevalent cardiovascular disease in kidney disease. Am J Nephrol. 2012;36:342-7.

22. Paul AK, Mash B, Rupesinghe G. Peripheral arterial disease - high prevalence in rural black south Africans. S Afri Med J. 2007;97:285-8.

23. Kalk P, Ruckert M, Godes M, et al. Does endothelin B receptor deficiency ameliorate the induction of peritoneal fibrosis in experimental peritoneal dialysis? Nephrol Dial Transplant. 2010;25(5):1474-8.

24. Kaneko K, Hamada C, Tomino Y. Peritoneal fibrosis intervention. Perit Dial Int. 2007;27(2):S82-6.

25. Modan M, Halkin H, Almog S, Lusky A, Eshkol A, Shefi M, et al. Hyperinsulinaemia: a link between hypertension obesity and glucose intolerance. J Clin Invest. 1985;75:809-17.

26. Assimacopoulos-Jeannet F, Brichard S, Rencurel F, Cusin I, Jeanrenaud B. Invivo effects of hyperinsulinaemia on lipogenic enzymes and glucose transporter expression in rat liver and adipose tissue. Metabolism. 1995; 44(2):228-33.

27. Bammens $B$, Evenepoel $P$, Verbeke $K$, Vanrenterghem $Y$. Time profiles of peritoneal and renal clearances of different uraemic solutes in incident peritoneal dialysis patients. Am J Kid Dis. 2005;46(3):512-9.

28. Schmidt S, Westhoff TH, Krauser P, Zidek W, Van der Giet M. The uraemic toxin phenylacetic acid increases the formation of reactive oxygen species in vascular smooth muscle cells. Nephrology Dialysis Transplantation. 2008; 23(1):65-71.

29. Rossi M, Campbell K, Johnson D, Stanton T, Pascoe E, Hawley C, et al. Uraemic toxins and cardiovascular disease across the chronic kidney spectrum: an observational. Study. Nutrition. Metabolism and cardiovascular diseases. 2014;24:1035-42.

30. Parikh NI, Hwang S, Larson MG. Cardiovascular disease risk factors in chronic kidney disease. Overall burden and rates of treatment and control. Arch Intern Med. 2006;166(17):1884-91.

31. Burmeister JE, Mosmann CB, Costa VB, Saraiva RT, Grandi RR, Bastos JP. Prevalence of cardiovascular risk factors in haemodialysis patients- the CORDIAL study. Arq Bras Cardiol. 2014;102(5):473-80.

32. Stein JH, Dougas PS, Srinivasan SR, Bond MG, Tang R, Li S, et al. Distribution and cross-sectional age-related increases of carotid artery intima-media thickness in young adults. Stroke. 2004;35:2782-7.

33. Khutan H, Aggarwal S, Kajal KS, Garg R, Kaur R, Kaur A. Study of carotid intima media thickness in essential hypertension with or without left ventricular hypertrophy. Ann Afr Med. 2017;16(4):192-5.

34. Lyons D, Roy S, Patel M, Benjamin N, Swift CG. Impaired nitric oxidemediated vasodilatation and total body nitric oxide production in healthy old age. Clin Sci. 1997;93:519-25.

35. Tirmenstajn-Jankovic B, Dimkovic N, Radojicic Z, Bastac D, Zivanovic M, Zikic S. Association between age and cardiovascular status by Echosonography in asymptomatic predialysis patients with chronic kidney disease. Saudi J Kidney Dis Transplant. 2017;28(4):818-29.

36. Messerli FH, Schmieder R. Left ventricular hypertrophy. A cardiovascular risk factor in essential hypertension. Drugs. 1986; 31 Suppl 4: 192-201.

37. Charytan D. Is left ventricular hypertrophy a modifiable risk factor in endstage renal disease. Curr Opin Nephrol Hypertens. 2014;23(6):578-85.

38. Levy D, Garrison RJ, Savage DD, Kannel WB, Castelli WP. Prognostic implications of echocardiographically determined left ventricular mass in the Framingham heart study. N Engl J Med. 1990;322:1561-6.

39. Weiner DE, Tighiouart $H$, Elsayed EF, Griffith $J L$, Salem DN, Levey AS, et al. The Framingham predictive instrument in chronic kidney disease. J Am Coll Cardiol. 2007:50:217-24.

40. Wilson PW, Castelli WP, Kanel WB. Coronary risk prediction in adults (the Framingham heart study). Am J Cardiol. 1987;59:91G-4G.

\section{Publisher's Note}

Springer Nature remains neutral with regard to jurisdictional claims in published maps and institutional affiliations.

\section{Ready to submit your research? Choose BMC and benefit from:}

- fast, convenient online submission

- thorough peer review by experienced researchers in your field

- rapid publication on acceptance

- support for research data, including large and complex data types

- gold Open Access which fosters wider collaboration and increased citations

- maximum visibility for your research: over $100 \mathrm{M}$ website views per year

At BMC, research is always in progress.

Learn more biomedcentral.com/submissions 